\title{
Selection algorithm for the CALIPSO lidar aerosol extinction-to- backscatter ratio
}

\author{
Ali H. Omar*a, David M. Winker ${ }^{\mathrm{a}}$, Mark A. Vaughan ${ }^{\mathrm{b}}$ \\ ${ }^{a}$ NASA Langley Research Center, Atmospheric Sciences, MailStop 401 A, Hampton, VA 2368 \\ ${ }^{\mathrm{b}}$ Science Applications International Corporation (SAIC) NASA Langley Research Center,
}

\begin{abstract}
The extinction-to-backscatter ratio $\left(\mathrm{S}_{\mathrm{a}}\right)$ is an important parameter used in the determination of the aerosol extinction and subsequently the optical depth from lidar backscatter measurements. We outline the algorithm used to determine $\mathrm{S}_{\mathrm{a}}$ for the Cloud and Aerosol Lidar and Infrared Pathfinder Spaceborne Observations (CALIPSO) lidar. $\mathrm{S}_{\mathrm{a}}$ for the CALIPSO lidar will either be selected from a look-up table or calculated using the lidar measurements depending on the characteristics of aerosol layer. Whenever suitable lofted layers are encountered, $\mathrm{S}_{\mathrm{a}}$ is computed directly from the integrated backscatter and transmittance. In all other cases, the CALIPSO observables: the depolarization ratio, $\delta$, the layer integrated attenuated backscatter, $\beta$, and the mean layer total attenuated color ratio, $\gamma$, together with the surface type, are used to aid in aerosol typing. Once the type is identified, a look-up-table developed primarily from worldwide observations, is used to determine the $\mathrm{S}_{\mathrm{a}}$ value. The CALIPSO aerosol models include desert dust, biomass burning, background, polluted continental, polluted dust, and marine aerosols.
\end{abstract}

Keywords: Aerosol, lidar, extinction-to-backscatter ratio

\section{INTRODUCTION}

$\mathrm{S}_{\mathrm{a}}$ is an intensive aerosol property, i.e., a property that does not depend on the number density of the aerosol but rather on such physical and chemical properties as size distribution, shape and composition. These properties are governed primarily by the source of the aerosol. The accuracy of the $S_{a}$ value used in the lidar inversions is dependent in part, on the correct identification of the type of aerosol. The CALIPSO aerosol typing will utilize observation data (both climatological and field campaigns), knowledge of emission sources inferred from surfaces types, and CALIPSO aerosol measurements such as depolarization ratio and the ratio of the backscatter coefficients at $1064 \mathrm{~nm}$ and $532 \mathrm{~nm}$, referred to as the color ratio, to identify aerosol type..

The importance of $\mathrm{S}_{\mathrm{a}}$ to lidar measurements is best illustrated by the solution of the single scattering lidar equation. While several solutions of the lidar equation are in use, we focus here on the Fernald solution [1]. For illustrative purposes consider a ground based lidar system with a field of view so small that the multiple scattering effects can be neglected. The single scattering lidar equation for such a system can be written as,

$$
N(z)=\eta \frac{P \Delta t}{h v} \frac{A}{4 \pi\left(z-z_{s}\right)^{2}} \beta_{T}(z) T^{2}\left(z-z_{s}\right) \Delta z,
$$

where $N(z)$ is the received signal photon count from a sample volume of thickness $\Delta z$ at altitude $z, \eta$ is the system efficiency, $\Delta \mathrm{t}$ is the measurement integration period, $\mathrm{P}$ is the average laser output power, $\mathrm{h} v$ is the photon energy, $\mathrm{h}$ is Planck's constant, $v$ is the optical frequency, $A$ is the receiving telescope area, $z_{\mathrm{S}}$ is the lidar site altitude, and $\beta_{\mathrm{T}}(\mathrm{z})$ is the total volume backscatter coefficient. $\mathrm{T}^{2}(\mathrm{z}-\mathrm{zs})$ is the two-way atmospheric transmission over the range $\mathrm{z}-\mathrm{z}_{\mathrm{s}}$,

$$
T^{2}\left(z-z_{s}\right)=\exp \left[-2 \int_{z_{s}}^{z} \sigma_{T}(l) d l\right]
$$

where $\sigma_{\mathrm{T}}$ is the total atmospheric extinction coefficient.

Both molecular and aerosol scattering contribute to the atmospheric extinction and backscatter coefficients,

ªli.h.omar@nasa.gov; phone:757-864-5128; fax 757-864-7790 


$$
\sigma_{T}(z)=\sigma_{m}(z)+\sigma_{a}(z),
$$

and

$$
\beta_{T}(z)=\beta_{m}(z)+\beta_{a}(z),
$$

where the subscripts (m) and (a) refer respectively to molecular and aerosol scattering. Molecular scattering varies inversely to the fourth power of the wavelength $\left(\sim \lambda^{-4.0117}\right)$, whereas the wavelength dependence of aerosol scattering depends on the size distribution, shape, and refractive index of the aerosol particles. The total backscatter coefficient $\beta_{\mathrm{T}}$ is calculated from the measured lidar profile using,

$$
\beta_{T}=\beta_{a}(z)+\beta_{m}(z)=\frac{X(z) \exp \left[-2\left(S_{a}(z)-S_{m}(z)\right) \int_{z_{0}}^{z} \beta_{m}\left(z^{\prime}\right) d z^{\prime}\right]}{\left[\frac{X\left(z_{0}\right)}{\beta_{a}\left(z_{0}\right)+\beta_{m}\left(z_{0}\right)}-2 S_{a}(z) \int_{z_{0}}^{z} X\left(z^{\prime}\right) \exp \left[-2\left(S_{a}(z)-S_{m}(z)\right) \int_{z_{0}}^{z^{\prime}} \beta_{m}\left(z^{\prime \prime}\right) d z^{\prime \prime}\right] d z^{\prime}\right]}
$$

where $X(z)=N(z)\left(z-z_{s}\right)^{2}, N(z)$ is given by Eq. 1.1, and $S_{a}=\sigma_{a} / \beta_{a}$ and $S_{m}=\sigma_{m} / \beta_{m}$ are the extinction to backscatter ratios for aerosol and molecular scattering. $\mathrm{S}_{\mathrm{m}}$ is known from theory and is equal to $8 \pi / 3$ sr. The reference altitude $\mathrm{z}_{0}$ is chosen where the aerosol scattering is negligible, i.e. $\beta_{\mathrm{a}}\left(\mathrm{z}_{0}\right) \sim 0$. The molecular backscatter coefficient profile is computed from theory using model atmosphere values for the temperature $T(z)$ and pressure $P(z)$. The value of $S_{a}$ on the other hand should be determined on a case by case basis and depends on the aerosol composition, size distribution, and shape.

Several measurements have been made to determine $S_{a}$ for different aerosol types. These measurements, primarily at $532 \mathrm{~nm}$, were performed using a variety of techniques, including Raman lidar [2-4], slant path techniques, and transmittance methods [5], and a nephelometer modified to directly measure extinction and near 180-degree backscatter [6]. The assumption that $S_{a}$ has a fairly constant value throughout the vertical column was widely used in the lidar community for several years. Recent studies $[7,8]$ have shown that $S_{a}$ can vary significantly with altitude.

\section{LEVEL II EXTINCTION PRODUCTS}

CALIPSO will produce two level II aerosol extinction products depending on the choice of the aerosol extinction-tobackscatter ratio: an approximate product and a CALIPSO extinction product. The approximate extinction product will be derived from a fixed $S_{a}$ ( 35 and $30 \mathrm{sr}$ at 532 and $1064 \mathrm{~nm}$, respectively). These values are chosen because they correspond to $\mathrm{S}_{\mathrm{a}}$ of the clean rural or background aerosol. AERONET analyses described below show that clean background aerosol is a frequently encountered aerosol type in the atmosphere [9]. In addition, experience with LITE measurements shows that these values are not likely to cause the failure of the extinction calculation. The CALIPSO extinction product is derived from $\mathrm{S}_{\mathrm{a}}$ based on the best estimate developed using CALIPSO measurements and the most up-to-date field observations. This paper discusses methods of making this estimate and describes an algorithm to achieve this.

\section{3. $S_{A}$ FOR LOFTED AEROSOL LAYERS}

The transmittance method requires clear air above and below the layer so that the transmittance through the layer can be determined. Fig. 3.1 is an example of an aerosol layer lofted above a clear air region at $1 \mathrm{~km}$. The transmittance method uses the following equation describing the relationship between optical depth and integrated attenuated backscatter:

$$
\gamma^{\prime}=\frac{2 \pi}{\eta S_{a}}(1-\exp (-2 \eta \tau))
$$

Here $\gamma^{\prime}$ is the integrated (from layer top to base) attenuated backscatter defined by, 


$$
\gamma^{\prime}=\int_{\text {top }}^{\text {base }} \beta_{a}(r) T_{a}^{2}(r) d r
$$

$\tau$ is optical depth, $\eta$ is a multiple scattering parameter. The quantities $\gamma^{\prime}$, and $\tau$ describe characteristics of a feature, i.e., they are associated with the backscatter and/or extinction of particles only. Note that the effective two-way transmittance is $T^{2}=\exp (-2 \eta \tau)$. If we define an effective $S_{a}, S^{*}=\eta S_{a}$, we can rewrite Eq. 3.3 as follows:

$$
S^{*}=\frac{1-T^{2}}{2 \gamma^{\prime}} \text {. }
$$

The effective two-way transmittance is typically obtained by fitting the return both above and below a feature to a reference profile [5].

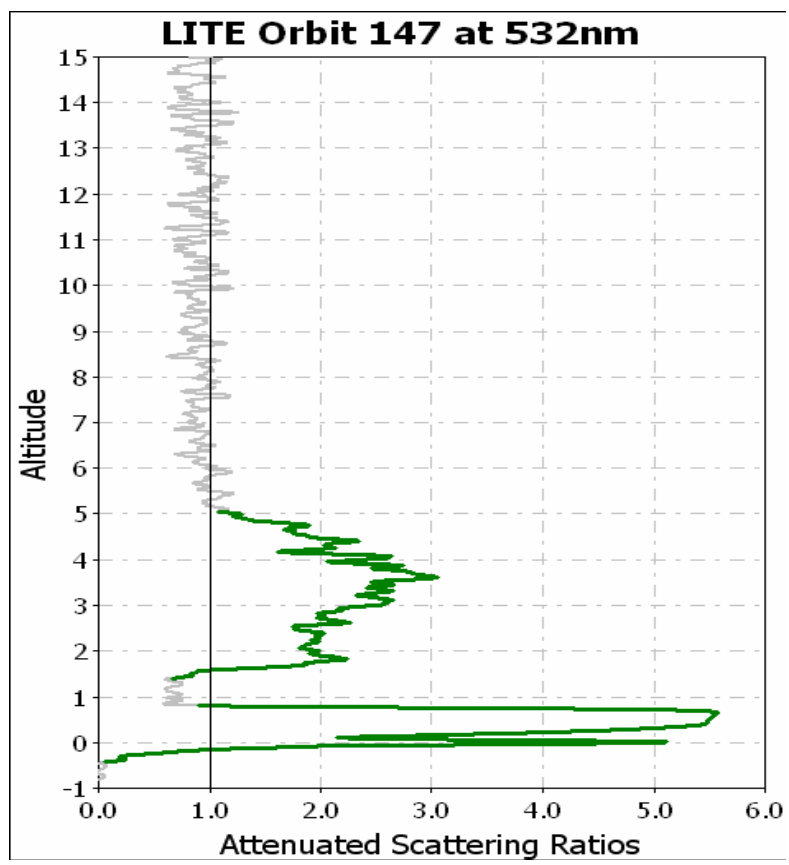

Fig. 3.1 The attenuated scattering ratios of a LITE return showing a case when the $\mathrm{S}_{\mathrm{a}}$ value can be calculated directly using the transmittance method

\section{4. $S_{A}$ SELECTION FROM LOOK-UP-TABLES}

One of the objectives of the algorithm is to estimate the appropriate value of $\mathrm{S}_{\mathrm{a}}$ within $30 \%$ of the true value. The strategy is to identify aerosol type and then use a look-up table to select values of $S_{a}$ and $\eta$ appropriate for the layer. The selection scheme uses the observed backscatter strength and depolarization to identify aerosol type, to the extent possible, from among one of the six types. In most cases, the depolarization is directly related to the hydration state of the aerosol. The backscatter and depolarization are not sufficient to fully constrain the model selection, however. Therefore, additional data is used to narrow down the choices of aerosol types based on the lidar observables. The selection algorithm uses the lidar observables and the International Geosphere-Biosphere Programme (IGBP) surface types. The land/water mask is based on the World Vector Shoreline (WVS) product for coastal information, and the Digital Chart of the World (DCW) for inland water areas.

\section{AEROSOL TYPES FROM AERONET}

Aerosol type is highly variable on time scales as short as a few hours [10]. Aerosol optical measurements must therefore be made at short time scales (about 30 minutes) to develop a large data base which can be used to derive statistically 
significant correlations and from which type-specific characteristics can be deduced. The AERONET measurements are likely to provide such a data base albeit for total column rather than vertically-resolved measurements. Cluster analysis was used for grouping multi-year AERONET data set based on several optical and physical characteristics of the aerosol [9].

This study used whole AERONET archive (up to December 2002) of measurements and inversions to develop a typespecific set of mean optical properties of aerosols. Since the clustering algorithm we used requires a fixed number of clusters a priori, this number is determined by using successively higher numbers of clusters until no new significant clusters are formed. The data clusters formed in this way group all records that have statistically significant similarities in one category. Details of the analyses methods can be found in [9]. We discuss below the results of the cluster analysis for the aerosol types and the distributions of $\mathrm{S}_{\mathrm{a}}$ at $532 \mathrm{~nm}$. The clustering analysis yields six distinct types of aerosols and each of these has distributions of the descriptive optical parameters used in the analysis. In this classification, polluted continental refers to a lightly-loaded soot-free pollution normally found in rural areas and is good approximation for rural aerosol. Dirty pollution refers to pollution containing significant amounts of absorbing species. Desert dust is assumed to be mostly mineral soil. Biomass burning is an aged smoke aerosol consisting primarily of soot and organic carbon. Polluted marine aerosol consists primarily of seasalt with traces of polluted continental species.

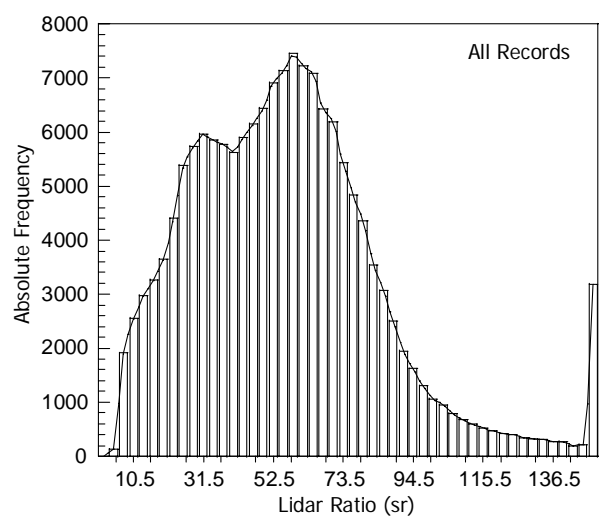

Fig. 5.1 Distribution of all $\mathrm{S}_{\mathrm{a}}$ values at $532 \mathrm{~nm}$

Both urban and dirty pollution consist of the same species but the large imaginary part of the refractive index of dirty pollution suggests that this type of aerosol contains a significantly larger (than urban) fraction of soot. Fig 5.1 shows the distribution of $S_{a}$ for all records. Table I shows the mean and standard deviation (std. dev) of $S_{a}$ for the six aerosol types. An $S_{a}$ value of $32 \pm 6 \mathrm{sr}$ for the clean northern hemisphere aerosol was measured during Aerosols99 [11]. A similar aerosol termed 'background-like' aerosol and originating on the European continent but devoid of any strong biomass or fossil fuel burning signature yielded an $S_{a}$ value of $35 \mathrm{sr}$ [7]. The value estimated by this study for clean continental is slightly higher than these values mostly because the clean continental AERONET sites are not very pristine.

The polluted marine $S_{a}$ value of 51sr is significantly larger than that measured during the SEAS experiment [12], and other estimates of $S_{a}$ for marine aerosols ranging between 20-30 sr [13-15].

The biomass burning value of $58 \mathrm{sr}$ is not at variance with the measurements of Voss et al. (2001) of $60 \pm 6 \mathrm{sr}$ off the west coast of Africa, Ansmann et al. (2001) of $70 \mathrm{sr}$ for biomass burning influenced aerosol advected from the Indian subcontinent during INDOEX. Recent studies of a limited climatology of 26 AERONET sites [16] at which biomass burning, coal combustion, urban/industrial, oceanic, and dust are the predominant types found $S_{a}$ values of $60 \pm 8$ sr for biomass burning.

In the case of desert dust, the AERONET retrievals used in the cluster analysis were based on the assumption of spherical particles. Dust particles are actually non-spherical, though, which has an unquantifiable effect on the accuracy of the results. The desert dust is lower than $S_{a}$ measurements by Voss et al. (2001) (41 \pm 8 sr) using a Micropulse Lidar for African dust, Sasano and Browell (1989) (52 $\pm 10 \mathrm{sr}$ ) and measurements of Liu et al. (2002) of Asian dusts (42 - 55 sr) found using a high-spectral-resolution lidar and a combined Raman elastic-backscatter lidar values.

Measurements by Ansmann et al. (2001) at the Sagres island off the Portuguese coast showed the $S_{a}$ value for pollution emanating from continental Europe to vary between 50 and 70 sr. During INDOEX measurements, $S_{a}$ values of polluted continental aerosol originating from northern and northeastern part of India, known for high emissions of black carbon, were made by Franke et al. (2001). They found values ranging from 49 to 70 sr. Measurements of a stagnant airmass at Bondville (a polluted continental site) yielded $S_{a}$ values of $64 \pm 4 \operatorname{sr}$ [17]. 
To check for the consistency of the individual categories, we divided the measurements in each category into five optical depth classes and plotted the $S_{a}$ of each class within a category. For each category, the magnitude of $S_{a}$ is fairly constant as shown in Fig. 5.2 below. The optical depth is an extensive property, i.e., a property that depends on the amount of aerosol. The Sa value on the other hand, is an intensive property and is relatively constant across optical depth classes within categories. This means that despite changes in the optical depth, the aerosol $\mathrm{S}_{\mathrm{a}}$ is consistently the same in each category. While this is not a sufficient validation of the clustering method, it is an indication of the ability of the algorithm to group similar data-sets using the prescribed variables.

Distributions of the $S_{a}$ values by type (Fig. 5.3) show that these are mostly single mode Gaussian for polluted continental, biomass burning, polluted marine, and dirty pollution and somewhat bimodal for dust and clean continental. The $S_{a}$ values obtained from the AERONET measurements have several limitations including assumptions about the sphericity of the particles, homogeneity of the atmospheric column, and homogeneity of the aerosol layer. Despite these limitations, the study is useful in estimating (to first order) the variation of $S_{a}$ values and the corresponding phase functions by aerosol type and location. The phase functions of the six aerosol types are shown in Figure 4. This information is useful for the retrieval of optical depths from spaced-based lidar measurements such as the Cloud Aerosol Lidar and Infrared Pathfinder Spaceborne Observations (CALIPSO).

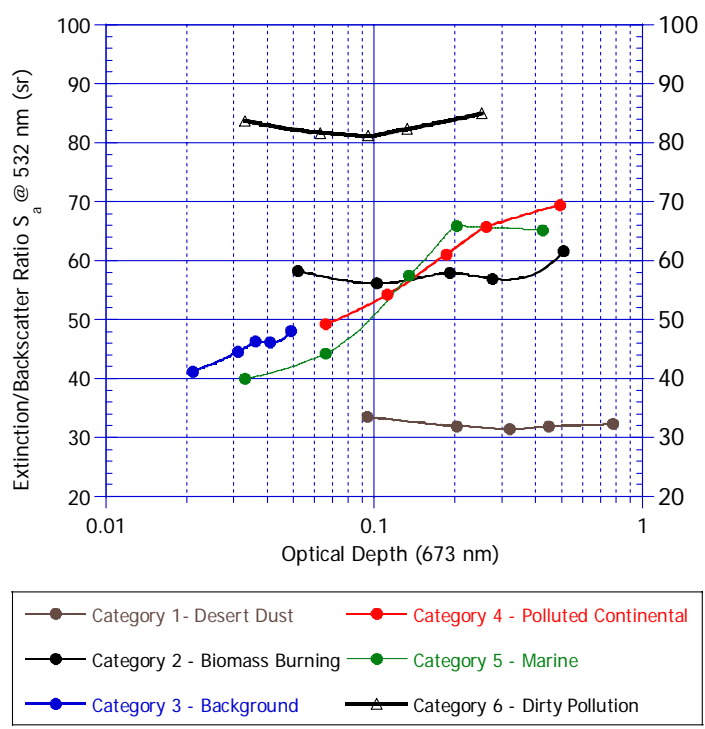

Fig. 5.2 Variation of the extinction/backscatter ratio over the optical depth within individual categories. For all the categories the variation with optical depth is small except for polluted continental and marine aerosols. 

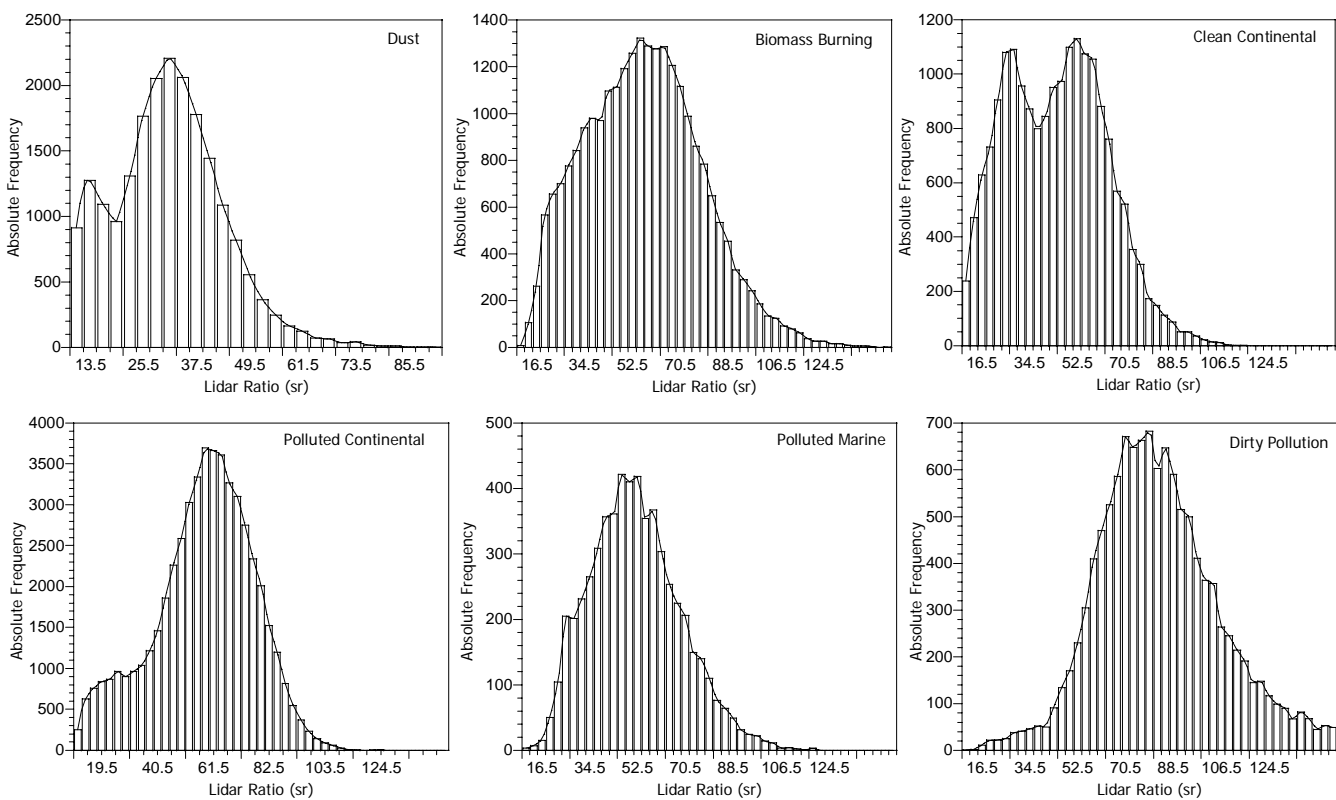

Fig. 5.3 Distributions of the extinction to backscatter ratios for the six aerosol types found by cluster analysis.

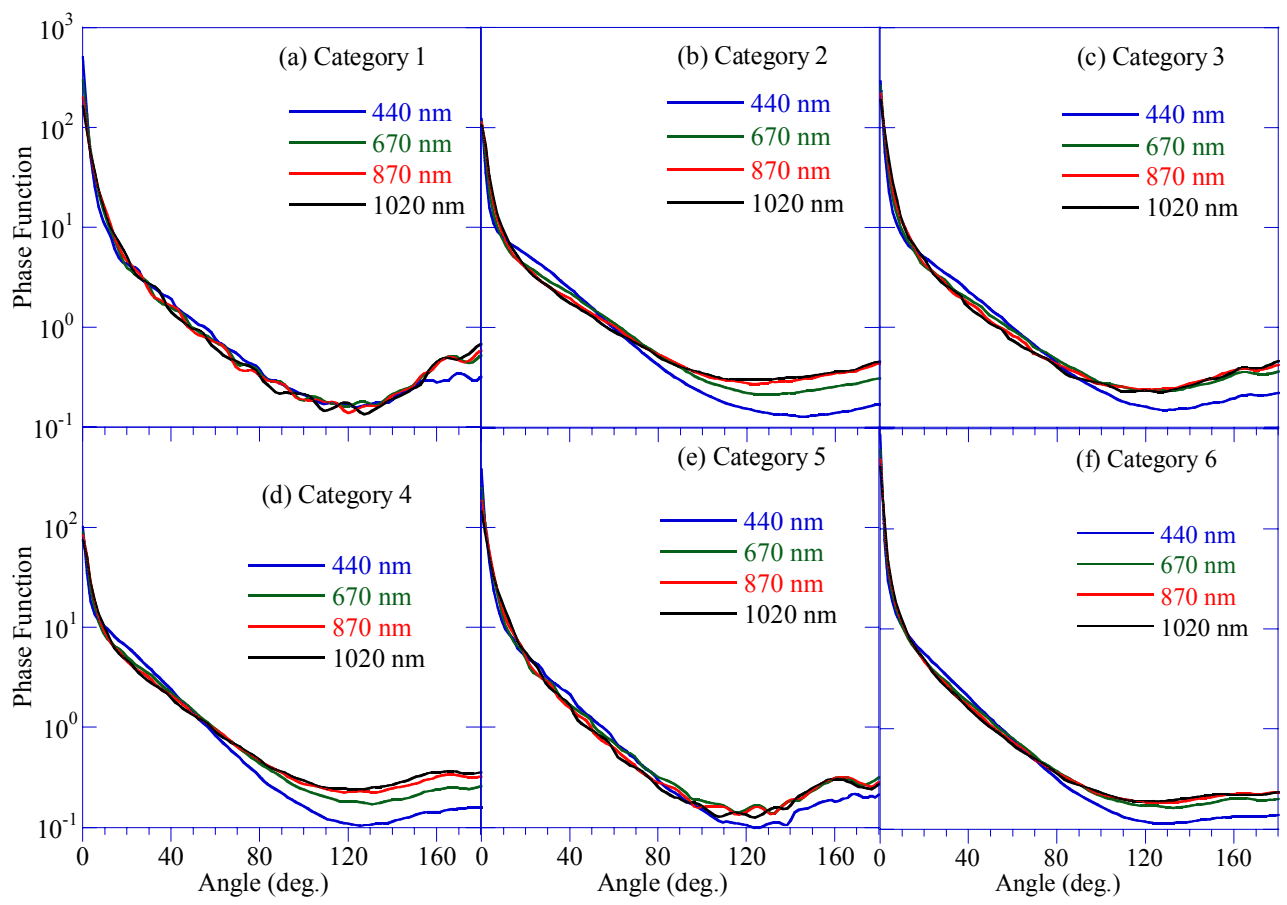

Fig. 5.4 Phase functions of the six aerosol types

Table 1. Extinction to backscatter ratio statistics for the six aerosol types

\begin{tabular}{|c|c|c|c|c|c|c|}
\hline & Dust & $\begin{array}{l}\text { Biomass } \\
\text { Burning }\end{array}$ & $\begin{array}{c}\text { Clean } \\
\text { Continental }\end{array}$ & $\begin{array}{c}\text { Polluted } \\
\text { Continental }\end{array}$ & $\begin{array}{l}\text { Polluted } \\
\text { Marine }\end{array}$ & $\begin{array}{c}\text { Dirty } \\
\text { Pollution }\end{array}$ \\
\hline No.of Records & 22202 & 26662 & 20307 & 55667 & 6527 & 12548 \\
\hline Mean (sr) & 32 & 58 & 45 & 58 & 51 & 83 \\
\hline Std. Dev. (sr) & 14 & 23 & 20 & 20 & 19 & 23 \\
\hline Minimum (sr) & 10 & 10 & 10 & 10 & 10 & 11 \\
\hline Maximum (sr) & 146 & 150 & 149 & 149 & 147 & 150 \\
\hline
\end{tabular}




\section{CALIPSO AEROSOL MODELS}
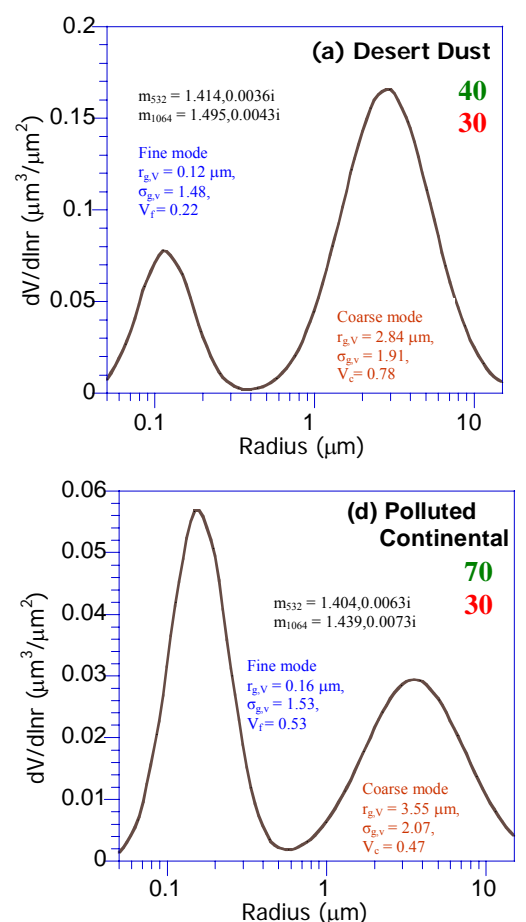
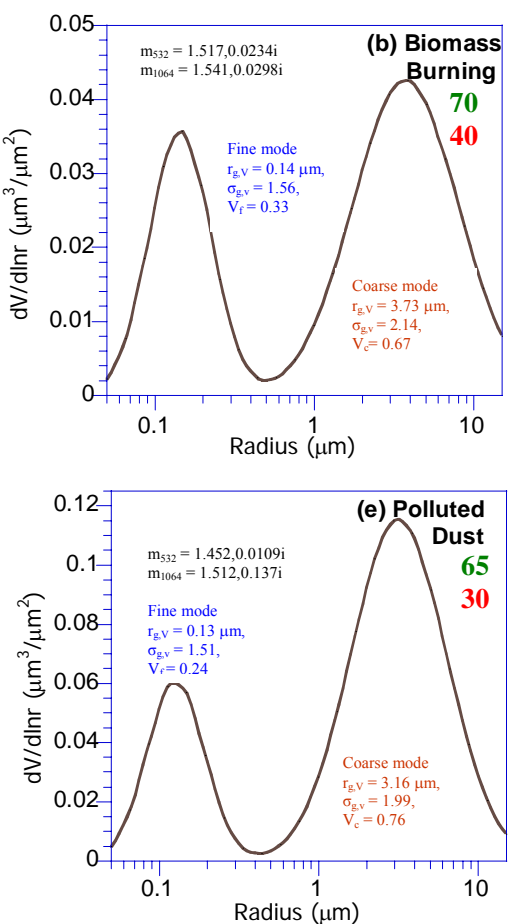
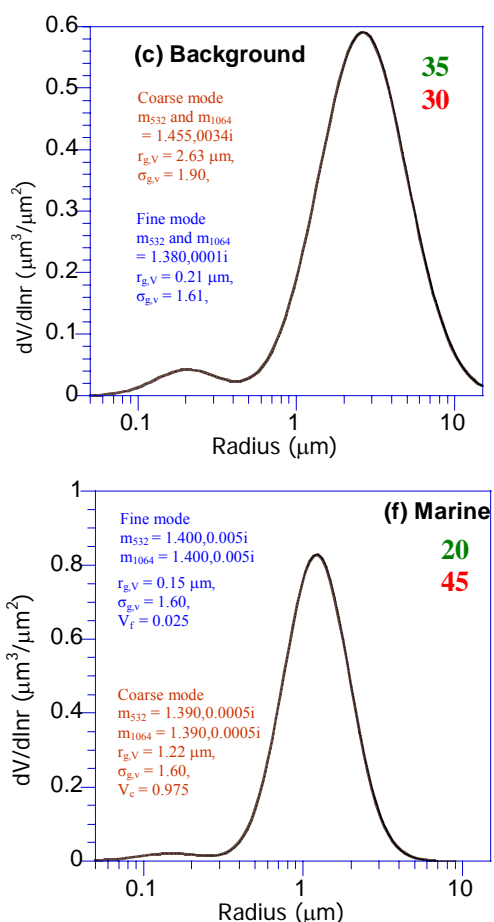

Fig. 6.1 The size distributions, and microphysical properties of the CALIPSO aerosol models. For each model, the $\mathrm{S}_{\mathrm{a}}$ (in sr) at $532 \mathrm{~nm}$ and $1064 \mathrm{~nm}$, is shown in green and red numbers, respectively. $r_{g, v}$ and $\sigma_{g, v}$ are the geometric mean radii and standard deviations of the distribution respectively. $\mathrm{m}_{\mathrm{i}}$ is the complex refractive index at wavelength $\mathrm{i}$

Some of the CALIPSO aerosol models were derived from AERONET clusters. Fig. 6.1 (a)-(f) show the physical and chemical properties of the CALIPSO aerosol models and the corresponding $\mathrm{S}_{\mathrm{a}}$ values at $532 \mathrm{~nm}$ (green) and $1064 \mathrm{~nm}$ (red). The AERONET cluster analysis yielded six distinct types of aerosol. Only three of these clusters (desert dust, biomass burning, polluted continental) were used to characterize the CALIPSO aerosol models. The CALIPSO model of background and marine aerosols are not derived from the AERONET measurements.

The AERONET records of the background cluster had low mean optical depths $(<0.05$ at $673 \mathrm{~nm})$. The microphysical properties derived from these are likely to have large uncertainties [18]. The CALIPSO background aerosol model (Fig. 6.1c) was derived by fitting size distributions and refractive indices to measurements of $\mathrm{S}_{\mathrm{a}}$ of long-range continental transport [6]. Note that the $\mathrm{S}_{\mathrm{a}}$ values for this aerosol type are used to generate the approximate extinction product described in section 2 above. The AERONET marine aerosol cluster is comprised of a small number of records $(<4 \%$ of the total). The CALIPSO marine aerosol model (Fig. 6.1f) is derived from the parameters measured during the SEAS experiment[12]. The CALIPSO polluted dust is a mixture of the AERONET desert dust and biomass burning clusters (Fig. 6.1e).

\section{7. $\mathrm{S}_{\mathrm{A}}$ SELECTION SCHEME}

The input parameters - the magnitude of attenuated backscatter, altitude, location, surface type, depolarization ratio, and mean attenuated backscatter coefficient measurements - are used to identify the type following one of eleven pathways in Fig. 7.1. In Fig. 7.1, pathway 1 is a lightly loaded aerosol layer found over snow/ice/tundra regions such as Antarctica and the clean Artic. Arctic haze, by virtue of the high integrated backscatter value, will be classified as polluted continental following pathway 2. Desert dust (Pathway 4) is expected to have a volume depolarization ratio greater than 0.2 and should be the predominant selection pathway for layers with substantial fractions of non-spherical particles. Pathways 3 and 5 allow for mixing with biomass burning smoke which will depress the volume depolarization ratio to a value below 0.2. Pathway 6 is a clean non-desert land surface at which the aerosol loading is close to the background values. Pathway 7 is a highly polluted land surface such as would be found in urban areas. Pathway 8 accounts for continental pollution advected off the coast and entrained in the marine boundary layer. Pathway 9 is marine boundary 
layer aerosol usually found in the deep ocean and consisting primarily of seasalt. Pathways 10 and 11 are elevated aerosol layers over land and ocean, respectively, of biomass burning smoke. Note that elevated dust layers are found in Pathway 4.

Studies are underway to determine optimum threshold values of $\delta, \beta$, and $\gamma$ to be used in the typing scheme. The values shown in Fig. 7.1 are initial estimates based on LITE measurements and, in the case of depolarization, on a limited set of observations and models [14, 19-22]. The goal is to base typing decisions on these observables as much as possible and avoid the use of geographic information. Therefore, the threshold values of $\delta, \beta$, and $\gamma$ are implemented as runtime parameters that can be adjusted using a configuration script. When lofted layers are encountered under favorable conditions, $\mathrm{S}_{\mathrm{a}}$ is computed directly from the integrated backscatter and transmission. We expect the algorithm will evolve significantly and the CALIPSO measurements will provide a much larger set of $\delta, \beta$, and $\gamma_{2}$ measurements than is currently available.

\section{Launch Build Lidar Ratio Selection Flow Chart}

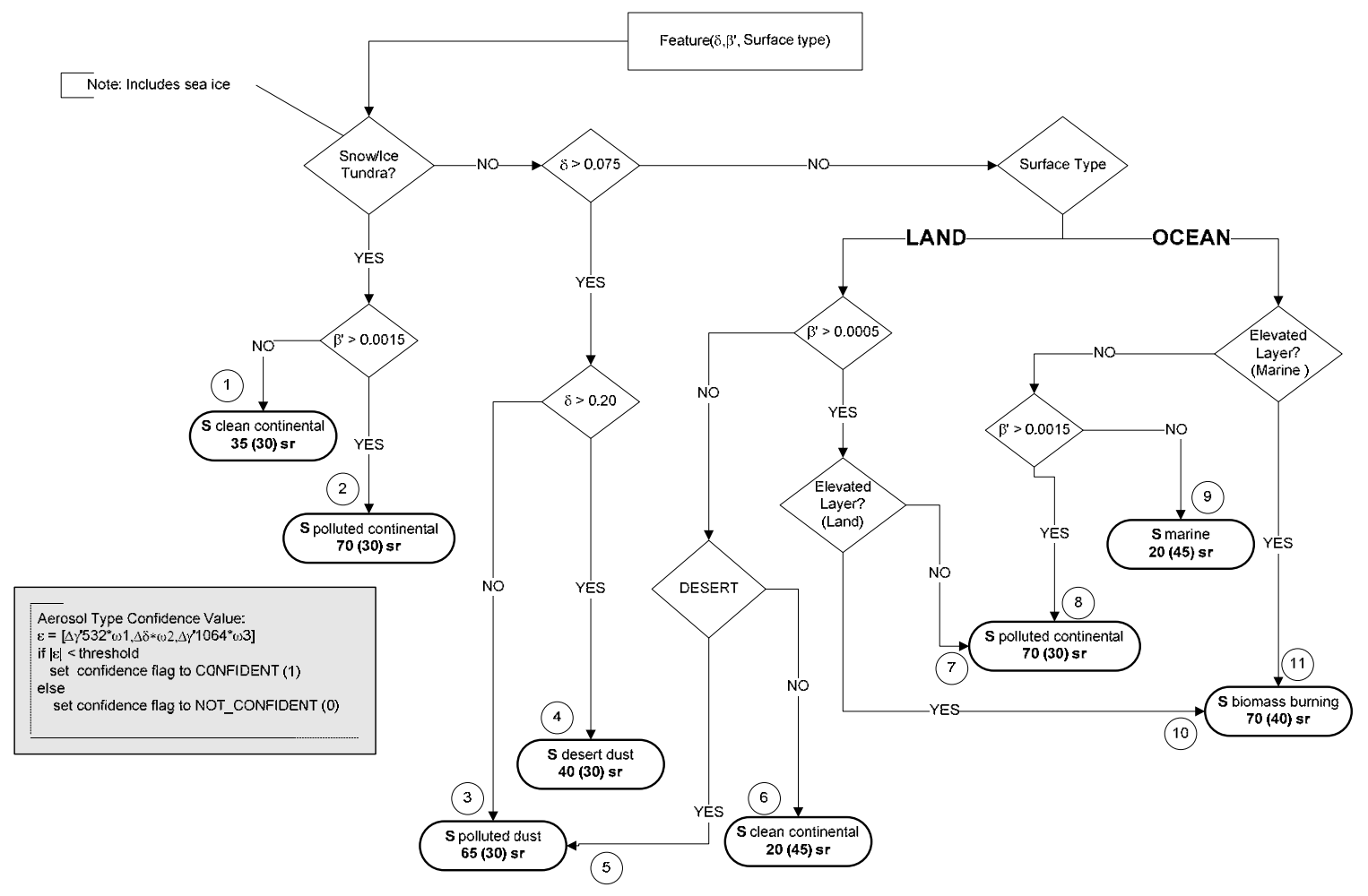

Fig. 7.1 Flowchart of the CALIPSO $\mathrm{S}_{\mathrm{a}}$ selection scheme for tropospheric aerosols. The values shown are the extinction-to-backscatter ratios at $532 \mathrm{~nm}$ and $1064 \mathrm{~nm}$ in parentheses. Note that the mean attenuated backscatter coefficient $\overline{\beta^{\prime}}=\gamma^{\prime} / \mathrm{z}$ where $\mathrm{z}$ is the layer thickness

\section{CONCLUSION}

An algorithm for determining aerosol type from knowledge of emission sources inferred from surfaces types, and CALIPSO aerosol measurements (such as depolarization ratio and the mean attenuated backscatter coefficients at 532 $\mathrm{nm}$ ) has been developed. These aerosol types are characterized using observation data from both climatological and field campaigns. The strategy identifies aerosol type and uses a look-up-table to assign an extinction-to-backscatter ratio to the aerosol layer.

A global data set, AERONET, has been used to identify main clusters of aerosol types and to determine microphysical properties of aerosol groups. This characterization is augmented by measurements where the uncertainty in the AERONET retrievals is high. New measurements from CALIPSO will significantly enhance this algorithm by making 
available a vastly improved data base of $\delta, \overline{\beta^{\prime}}$, and $\chi$. Such data sets will be used to further refine the probability

distribution functions and threshold values of $\delta, \overline{\beta^{\prime}}$, and $\chi$ used in the algorithms. The flowchart in Fig. 7.1 is therefore a preliminary selection scheme. This approach will ensure that the science mission requirements for optical depth accuracy of $40 \%$ error assuming a $30 \%$ uncertainty in the extinction-to-backscatter ratio will be realized.

\section{REFERENCES}

1. F. G. Fernald, Analysis of Atmospheric Lidar Observations: Some Comments, Applied Optics, vol. 23, pp. 652-653, 1984.

2. D. Müller, et al., Physical Properties of the Indian Aerosol Plume Derived from Six-Wavelength Lidar Observations on 25 March 1999 of the Indian Ocean Experiment, Geophysical Research Letters, vol. 27, pp. 1403-1406, 2000.

3. R. A. Ferrare, et al., Raman Lidar Measurements of the Aerosol Extinction-to-Backscatter Ratio over the Southern Great Plains, J. Geophys. Res., vol. 106, pp. 20333-20347, 2001.

4. K. Franke, et al., One-Year Observations of Particle Lidar Ratio over the Tropical Indian Ocean with Raman Lidar, Geophysical Research Letters, vol. In press, 2001.

5. S. A. Young, Analysis of Lidar Backscatter Profiles in Optically Thin Clouds, Applied Optics, vol. 34, pp. 7019-7031, 1995.

6. T. L. Anderson, et al., In Situ Measurements of the Aerosol Extinction-to-Backscatter Ratio at a Polluted Continental Site, J. Geophys. Res., vol. 105, pp. 26907-26915, 2000.

7. A. Ansmann, et al., European Pollution Outbreaks During Ace 2: Lofted Aerosol Plumes

Observed with Raman Lidar at the Portuguese Coast, Journal of Geophysical Research, vol. 106, pp. 20725-20733, 2001.

8. R. A. Ferrare, et al., Raman Lidar Measurements of the Aerosol Extinction-to-Backscatter Ratio over the Southern Great Plains, Journal of Geophysical Research, vol. 106, pp. 20333-20347, 2001. 9. A. H. Omar, et al., Development of Global Aerosol Models Using Cluster Analysis of Aerosol Robotic Network (Aeronet) Measurements, J. Geophys. Res., vol. 110, 2005.

10. P. J. Sheridan, et al., Four Years of Continuous Surface Aerosol Measurements from the Department of Energy's Atmospheric Radiation Measurement Program Southern Great Plains Cloud and Radiation Testbed Site, J. Geophys. Res., vol. 106, pp. 20735-20747, 2001.

11. K. J. Voss, et al., Lidar Measurements During Aerosols99, Journal of Geophysical Research, vol. 106, pp. 20821-20831, 2001.

12. S. J. Masonis, et al., A Study of the Extinction-to-Backscatter Ratio of Marine Aerosol During the Shoreline Environmental Aerosol Study, Journal of Atmospheric and Oceanic Technology, vol. 20, pp. 1388-1402, 2002.

13. C. Flamant, et al., Wind Speed Dependence of Atmospheric Boundary Layer Optical Properties and Ocean Surface Reflectance as Observed by Airborne Backscatter Lidar, J. Geophys. Res., vol. 103, pp. 25137-25158, 1998.

14. J. A. Reagan, et al., Lidar Aerosol Ratio: Measurements and Models, presented at International Geosciences and Remote Sensing Symposium (IGARSS), Sidney, Australia, 2001.

15. A. Ansmann, et al., European Pollution Outbreaks During Ace 2: Lofted Aerosol Plumes Observed with Raman Lidar at the Portuguese Coast, J. Geophys. Res., vol. 106, pp. 20725-20733, 2001.

16. C. Cattrall and J. Reagan, Variability of Aerosol Lidar, Backscatter and Extinction Ratios 
of Key Aerosol Types Derived from Selected Aeronet Locations, J. Geophys. Res., vol. In Review, 2005.

17. T. L. Anderson, et al., In Situ Measurements of the Aerosol Extinction-to-Backscatter Ratio at a Polluted Continental Site, Journal of Geophysical Research, vol. 105, pp. 26907-26915, 2000.

18. O. Dubovik, et al., Variability of Absorption and Optical Properties of Key Aerosol Types Observed in Worldwide Locations, Journal of Atmospheric Sciences, vol. 59, pp. 590-608, 2002.

19. G. P. Gobbi, et al., Altitude-Resolved Properties of a Saharan Dust Event over the Mediterranean, Atmospheric Environment, vol. 34, pp. 5119-5127, 2000.

20. T. Murayama, et al., Application of Lidar Depolarization Measurement in the Atmospheric Boundary Layer: Effects of Dust and Sea-Salt Particles, J. Geophys. Res., vol. 104, pp. 3178131792, 1999.

21. T. Sakai, et al., Raman Lidar and Aircraft Measurements of Tropospheric Aerosol Particles During the Asian Dust Event over Central Japan: Case Study on 23 April 1996, J. Geophys. Res., vol. 108, pp. 4349, 2003.

22. M. J. McGill, et al., Airborne Lidar Measurements of Aerosol Optical Properties During Safari2000, J. Geophys. Res., vol. 108, 2003. 